\title{
De la novela al CD-ROM. El desierto malva de Nicole Brossard'
}

Denis Bachand

Universidad de Ottawa, Canadá

Traducción del francés: Silvia Zenarruza

La literatura siempre ha mantenido relaciones particulares con los diferentes medios que han aparecido en el fragor de las innovaciones tecnológicas. Desde la invención de la imprenta hasta la aparición de la prensa de grandes tiradas, a la radio y la televisión y pasando por el cine que se inspira ampliamente de él, el campo literario aparece como un reservorio inagotable de personajes, intrigas, leyendas y mitos aptos para estimular el imaginario de los creadores de contenidos de los nuevos medios.

Los juegos electrónicos rebosan igualmente de referencias a ciertos relatos canónicos de la literatura confirmando esta alianza fundada en imperativos económicos y culturales. Las editoriales han comprendido rápidamente la importancia de los nuevos hábitos de lectura suscitados por el advenimiento de la tecnología digital. Es por esto que se han dedicado a los productos multimedia adaptando algunos "valores seguros" y varios títulos han aparecido ya en el mercado: El principito de Saint- Exupéry (Gallimard, 1997), El mundo de Sophia de Jostein Gaarder (Seuil, 1997), Robinson Crusoe de William Defoe (Flammarion, 1997), Los viajes extraordinarios de Julio Verne (Hachette, 1998), Los ciento un poemas de Paul Eluard (Arte Éditions / Softissimo, 1995), Shéhérazade (Arborescente, 1996), Pilgrim de Coello y Moêbius (Infogrammes/Artxel Tribe, 1997). Sin embargo, hasta ahora, pocas obras de Québec han sido objeto de tal operación. Que sepamos, la primera novela que haya sido transportada sobre CD-ROM es Le désert mauve (El desierto malva) de Nicole Brossard (L'Hexagone, 1987) por la artista californiana Adriene Jenik².

Esta obra servirá de anclaje a nuestra reflexión sobre la adaptación de lo escrito al multimedia. Deseamos así extraer las particularidades de esta nueva forma de escritura emergente que se construye en la tensión entre lo que toma prestado de prácticas artísticas emparentadas y su necesidad de autonomización. ${ }^{3}$

El caso de Mauve Desert tiene la particularidad de que invita explícitamente a reflexionar tanto sobre la narración (de las anécdotas) de la novela de origen como sobre la puesta en abismo formalizada en la producción propiamente dicha del CD-ROM. Este encabalgamiento respeta la estructura especular del hipotexto y permite reflexionar al mismo tiempo sobre el plano del significante y el del significado a través de las redes de las que la traductora intenta, como lo sugiere Christine Klein-Lataud, "[...] extraer la poética de la autora a fin de adoptar el mismo procedimiento creativo. Imitar no el texto sino el acto de escritura tal como se lo reconstituye (o se cree reconstituir) a través del texto"4. Por lo tanto, un segmento de la narración de origen convoca a su reinterpretación a través de resonancias biográficas en la obra del artista multimedia, confirmando que la adaptación constituye aquí una verdadera crítica de identificación hipermediática. 
En un sentido, la estructura de la novela de Nicole Brossard prefigura doblemente su tratamiento hipertextual ${ }^{5}$. Por una parte, el tema de la traducción que es central allí es retomado en forma paratextual en el subtítulo para circunscribir el pacto genérico: "...a CD-ROM translation of Le désert mauve". La multimediatización del texto primero redobla de alguna manera el proceso de traducción intradiegética propuesto por la novela misma. Esta última está en efecto constituida por tres secciones principales: la novela original firmada Laure Angstelle que da su título epónimo al conjunto de la obra de Nicole Brossard (Le désert Mauve), el trabajo de traducción de Maude Laures (Un libro para traducir, y Un libro para traducir [continuación]), y finalmente la versión traducida del primer texto (Mauve, l'horizon). Por otro lado, cada una de estas partes está igualmente constituida por un cierto número de sub-secciones compuestas por bloques textuales intercalados que se prestan a un recorrido de lectura no lineal de tipo hipertextual en el sentido informático del término. Por otra parte, la autora nos informa en el epígrafe, citando a Italo Calvino -al que muchos identifican con Queneau, Caroll, Pérec y Borges como autores "preelectrónicos" - que: "Leer, es ir al encuentro de algo que va a existir pero de lo que nadie sabe todavía lo que será..." La pista constructivista de tipo hipertextual queda así trazada. Y los paseos en auto de Melanie por el desierto se impondrán como un modo de pasaje privilegiado hacia el multimedia. Al receptor no le queda más que ocupar una postura de lectura en focalización interna que le acuerda su inscripción metafórica "en el asiento del conductor" (como lo sugiere una nota del aparato paratextual a guisa de modo de empleo), para ir al encuentro de esa cosa (el recorrido del sentido a través del sentido del recorrido) que progresivamente se construye en el juego de las idas y venidas entre los diferentes segmentos del texto multimediático.

La metáfora de navegación funciona como un pacto de lectura que determina la posición del receptor conativamente interpelado por el dispositivo que lo impulsa a activar los botones que permiten migrar de un bloque audio-scripto-visual a otro, de una lexia a otra. ¿Cuál es la naturaleza de este nuevo dispositivo de lectura y expectación -la del cine, del juego video, de la literatura? ¿Qué estrategias dirigen esta interfaz de pantalla que es sensible a la intencionalidad de la búsqueda de sentido por parte de un inter-actor? El pasaje de lo escrito a un medio electrónico ¿Contribuye al enriquecimiento de la obra? ¿De qué maneras? ¿Cómo esas nuevas modalidades de apropiación de la obra reconfiguran la instancia de la recepción? En suma, ¿¿de qué manera la adaptación multimediática, en tanto que manifestación de un recorrido de lectura específico, se ha adaptado a los códigos de una nueva tecnología que, a su vez, le ha prestado nuevas dimensiones estéticas, hermenéuticas y críticas?

Presentada en la contratapa como una primera novela "posmoderna" del Québec, Le désert mauve funciona sobre la autoreferencialidad señalada por la muestra de los códigos, típicos de las obras que pertenecen al movimiento del Nouveau Roman que deseó quebrar las convenciones del realismo ficcional. Nicole Brossard ha construido la novela de la estructuración de su novela tematizando el proceso genésico y genérico de conversión de una obra en otra. La autora juega allí de hecho como traductora de su propia creación produciendo las variantes de su propio texto. Primera novela (doblemente pre/texto) que se presenta como el libro de una ilustre desconocida, Laure Angstelle, descubierta en una librería por Maude Laures quien, constatando su fascinación, no tiene más alternativa que traducir su contenido para apropiárselo y domesticarlo, operando así una crítica de identificación por la vía del pastiche a la manera de Proust para quien leer "...es tratar de imitar en el fondo de sí el gesto creador que el libro nos revela y nos incita a imitar”" Así pasará 
varios meses anotando el texto que relata las peripecias fogosas de la joven Mélanie, su vida en medio del desierto entre su madre (Kathy Kerouac) y la amante de esta última (Lorna Myer), su búsqueda de felicidad junto a Angela Parking quien será asesinada bailando en sus brazos.

Las dos figuras de escritoras ficticias actúan como verdaderos avatares de la autora Nicole Brossard, e intervienen según voces narrativas diferentes como lo ha demostrado Lucie Hotte ${ }^{8}$. Laure Angstelle ocupa sucesivamente dos posiciones enunciativas. Se disimula detrás del personaje principal de Mélanie quien le presta su visión mediante la cual se produce una focalización interna, y adopta una focalización cero cuando relata los episodios del hombre largo, los que no tienen ningún lazo aparente con el relato principal. Maude Laures, por el contrario, emplea el pronombre personal yo en la sección Un livre à traduire (Un libro para traducir): "desde que releo este libro, estoy anclada en un punto cero..." (p. 147), aunque reproduce las voces narrativas concordantes del texto de Laura Angstelle en su traducción Mauve, l'horizon. Le désert mauve tematiza así la desterritorialización, el desplazamiento, la descontextualización y la errancia, tanto en su contenido como en su forma. La novela alcanza todo su sentido y su originalidad en la parte media del tríptico, la que brinda una oportunidad a la instancia autorial (Brossard), primero por medio del punto de vista narrativo omnisciente de Maude Laures (Un livre à traduire), luego del suyo propio como narradora todo-poderosa (Un livre à traduire (suite)): "Hacía ya más de un año que Maudes Laures preparaba su manuscrito" (en cursiva en el texto, p. 169), y al proceder a la diegetización de los procesos de producción del texto de traducción por medio de la puesta en abismo de un entretejido de voces narrativas. Están allí representadas, en suma, simultáneamente, la génesis de la obra traducida y el cuestionamiento crítico que acompaña al trabajo de reescritura.

¿Cómo se declina cada una de estas dimensiones en la adaptación multi-mediática? ¿Cómo se orquesta el conjunto de los puntos de vista? ¿Qué se ha preservado de los programas narrativos para que la transferencia permanezca fiel al modo? ¿De qué manera Adriene Jenik se inscribe en continuidad poética con la instancia autoral del texto literario? ¿Cómo restituye el espíritu y la letra del texto original recurriendo a las posibilidades del medio informático? ¿En qué medida el multimedio informático interactivo se presta más que el film, opción pensada en un primer momento por la autora, para la restitución de la obra?

Estas cuestiones son constitutivas de la problemática general desarrollada al examinar transformaciones sufridas por la novela en el momento de su conversión al multimedia interactivo. Procederemos al análisis de la hibridación de configuraciones audio-scripto-visuales generadas para restituir el texto de origen constituido de una materia y una forma lingüísticas y parcialmente visuales: las fotos del personaje del hombre largo en una habitación de motel y el grafismo que simula las ediciones de las dos novelas.

Observemos antes que nada que el texto, objeto de la adaptación, está constituido por las dos primeras secciones del tríptico novelesco, mientras que la producción multimedia replica de alguna manera en su misma materialidad la última parte, esto es la traducción propiamente dicha. De manera que se puede considerar que el punto de vista privilegiado por la artista multimedia es el de un substituto de la traductora intradiegética, Maude Laures.

La obra se abre en una primera página que muestra gráficamente un sistema de envíos formados por lazos diversos (lineales y arborescentes ${ }^{9}$ ) a los que se accede ya sea en inglés, ya en francés: la descripción de los personajes; el modo de uso del dispositivo de navegación; los créditos; la sinopsis de la novela de origen tal como 
se la puede leer en la contratapa y el comienzo propiamente dicho que permite encarar la exploración. En voz over una presentación en inglés del proyecto "una traducción CD-ROM de Le désert Mauve de Nicole Brossard" nos introduce a su recorrido con el fondo de una imagen del letrero intermitente de un Motel. El receptor puede ir en la dirección que elija seleccionando uno u otro de los segmentos activados a este fin. Ninguna dirección precisa le es impuesta. Una vez hechas estas primeras incursiones, se sigue la invitación a "comenzar..." inscripta convencionalmente al pie de la pantalla, a la derecha.

Al final de una corta escena video que reúne a Mélanie y a su madre en el momento en que la adolescente toma el automóvil para dar un paseo, se engancha automáticamente un dispositivo nodal de navegación, esto es el interior del automóvil visualmente captado por encima del hombro de Mélanie con la cual el lector comparte la visión. Un travelling hacia delante muestra el paisaje de una ruta aislada con una banda sonora hecha con música y letras que retoman textualmente el comienzo del Désert mauve: "El desierto es indescriptible... el cielo es indescriptible (en español en el texto de origen)... the sky is indescribable... un gran árbol de vida en mi mirada...", atrapando al lector en una polifonía multilingüe: francesa, inglesa y española. Contrariamente a la novela de origen que propone una variante textual de una misma lengua, la versión multimedia corresponde verdaderamente a una traducción donde se opera un enriquecimiento de la obra por el recurso a la alteridad lingüística.

El desenlace de esta primera secuencia de apertura llama a otro elemento nodal mayor del dispositivo, esto es el mapa de rutas de Mélanie (Melanie’s map) sobre el cual están inscriptos los trayectos tomados por la adolescente (ilustración 1). Su gran potencial de esquematización y su fuerte codificación cultural hacen del mapa una metáfora de ubicación muy frecuentemente utilizada en los CD-ROMs. Según David Cohen, que ha analizado doscientas interfaces, ésta “(...) presenta la navegación en un CD como un sucedáneo de la estrategia militar o de la conducción de un automóvil, grandes consumidores de mapas"10. Se comprende su pertinencia aquí ya que el motivo del paseo está en el centro de este road movie literario. Sin embargo, sin una nota de empleo, el usuario busca a tanteos, siguiendo al azar las transformaciones del cursor en la pantalla, pasajes hacia esos lugares inscritos como participando de la historia: Desolation Canyon, Jacas Flat, Devil's Playground, Badwater, etc. Un total de dieciseis lugares forman esta topografía imaginada a partir de la extracción de segmentos textuales repartidos en el conjunto de los ocho capítulos que componen el relato de Laure Ansgtelle. La mitad de esos topos representa lugares reales mientras que los otros ocho son fruto de la imaginación creadora de la adaptadora. Esta simetría respeta el carácter dialógico del hipotexto al tiempo que inscribe elementos biográficos de apropiación; la taxonomía en efecto se ha inspirado del contexto geográfico de la cultura de llegada, el sudoeste de los Estados Unidos ${ }^{11}$. El llamado de estas secciones se hace por intermedio de enlaces visuales (textos, imágenes, pictogramas) y sonoros que dan acceso a informaciones sin que ninguna dirección precisa sea indicada. El interactor puede en cierto modo recorrer cada una de las lexias sin tener que respetar necesariamente un orden determinado. En un sentido, cada sesión está emparentada con un montaje que estructura de manera diferente la prosecución de la lectura. Pero ésta es menos compleja que en ciertos juegos video (Myst, Riven por ejemplo ${ }^{12}$ ) donde el éxito de pruebas transitorias es un imperativo para la realización de la conjunción final que impone el programa narrativo de base. Lo cierto es que el trabajo cognitivo invertido en la resolución de una serie de programas narrativos de uso se efectúa sobre un modelo lúdico fuertemente codificado por el género. 
En El desierto malva, el relato de Mélanie está sistemáticamente entrecortado por el relato paralelo del hombre largo. La figura insólita del asesino de Angela Parkins, especie de "demiurgo de la destrucción" convertido en el hombre oblongo en la traducción de Maude Laures, se alberga en los intersticios de la narración principal para demarcar sus ocho capítulos. Comparado a un "alambre invisible que separa la realidad de la ficción", está también representado en forma de fotos insertadas en un dossier de búsqueda incorporado a la sección media Un livre à traduire. La estrategia de adaptación ha consistido en interpretar esta alternancia aprovechando las posibilidades técnicas del medio digital que permite irrupciones espontáneas y aleatorias de imágenes fotográficas. Las rupturas lineales y simétricas han dado lugar a súbitas interrupciones las que, haciendo dudar del buen funcionamiento del CD-ROM, amplifican el efecto de quiebre que provoca un retorno al principio de realidad. Estas fracturas narrativas agregan así un efecto inusitado imposible de realizar en un soporte papel o aun por un montaje paralelo en el cine. Estamos en presencia de un rasgo específico de la multimedialidad electrónica explotado como prolongación crítica de la obra adaptada: la secuencionalidad simétrica interpretada como fractura e interposición que refrena el régimen ficcional.

La exploración prosigue desde el retorno al interior del auto donde el interactor está ubicado visualmente en posición de conductor. Primero en el lugar de Mélanie, logrando hasta mover su brazo para alcanzar ya sea la radio o la guantera, luego en posición por encima del hombro desde donde se puede percibir el rostro de la adolescente por circunvolución en el reflejo del retrovisor que juega un papel restitutiva <restitutivo > del recuerdo al mostrar segmentos videográficos (ilustración 2.) Esta memoria especular funciona en doble sentido ya que las secuencias animadas han sido compuestas a partir de una serie de planos filmados en ocasión de una primera versión cinematográfica abandonada porque se la juzgó inadecuada al tema ${ }^{13}$. El multimedia refleja de alguna manera lo cinematográfico redimensionándolo y situándolo en su anterioridad genealógica. La elección del medio de adaptación induce una estética particular, en este caso, la de la restitución de una lectura experimental irreductible a las convenciones del espectáculo. Esto no impide, sin embargo, que se proceda simultáneamente a una crítica de la interactividad como simulacro de autoría (auteurité).

Cada una de las secuencias del paseo está estructurada sobre el mismo modelo. La puntuación interactiva se presenta en él siempre mediante el recurso a la selección de una de las tres zonas activadas en la imagen que da acceso a las informaciones provenientes de otros tantos campos virtuales. La co-presencia de varios cuadros situados en el plano así como su utilización frecuente constituye según Cohen uno de los rasgos sintácticos fundamentales del multimedia ${ }^{14}$. En efecto, aunque la pantalla parcelada haya sido experimentada por un cierto cine, está muy lejos de haberse transformado en la norma mientras que más bien tendería a serlo en la estética del multimedia. Esta segmentación de la pantalla produce una plástica que contribuye al mestizaje de los signos típicos que participan de una nueva concatenación sintagmática donde las palabras, los objetos y las imágenes se convierten en objetos-signos de pasaje por vía indicial hacia hipertextos que les son contiguos.

Además, la ascendencia genética ejercida por el hipotexto está reactivada por la cita visual de las páginas anotadas de la novela las que se inscriben en el plano de fondo de las secuencias de los paseos. Los itinerarios de lectura están así configurados y reportados sobre el simulacro del libro contextualizado con anterioridad por la operación substitutiva de la espacialidad por la temporalidad. La utili- 
zación de la metáfora libresca es frecuente en los juegos video que recurren a ella como mito fundador de universo y de pasaje hacia lugares imaginarios (es en particular el caso de $M y s t)$. Recordar esto aquí es doblemente pertinente ya que el libro está en la base del trabajo de la traductora intradiegética y que su utilización se inscribe en la edificación de la codificación de un nuevo lenguaje. La preferencia del multimedia sobre el cine como media (medio) de adaptación se explica de alguna manera por las posibilidades acrecentadas de prolongación de la exploración del lenguaje que brinda el medio. La estratificación de los múltiples recorridos de lectura potenciales encuentra aquí un lugar de experimentación más propicio para la profundización de la relación entre los dos polos de la comunicación artística.

La estrategia del tablero de mandos, frecuentemente empleada como metáfora de ubicación en el multimedia, reviste aquí un sentido literal y su exploración depende del grado (bastante extenso) de familiaridad con la ergonomía del habitáculo. El interactor accionará los botones simulados del auto-radio para tener acceso a los segmentos virtuales ya sea en francés, en inglés o en español, lo que representa otro enriquecimiento de la adaptación. O elegirá abrir la guantera en la que se encuentra una serie de documentos que dan acceso también a otras ventanas del dispositivo: el mapa de rutas que nos permite encarar distintos paseos con Mélanie; el libro de la fabricación del CD-ROM que nos introduce al trabajo de la adaptadora propiamente dicho; un mapa de Montreal que permite enlaces con la autora Nicole Brossard quien puede intervenir por medio de segmentos de una entrevista (ilustración 3); la biblioteca que da acceso a ciertos títulos de obras que han servido para documentar la traducción; el personaje de la traductora intradiegética Maude Laures sentada frente a su mesa de trabajo; la descripción del revólver fatal responsable del desenlace final; el diario íntimo donde la joven que interpreta el papel de Mélanie ha consignado sus estados de ánimo.

La página titulada Un livre à traduire-A book to translate es otro ejemplo clásico de pantalla parcelada que reúne ocho vínculos hipermedias que conducen a otros tantos componentes del trabajo de Maude Laures (ilustración 4): los libros de la biblioteca; labios que articulan en francés o en inglés según la lengua elegida; un libro de documentación; una entrevista con el personaje de la traductora que explica su trabajo; un diccionario que da acceso a las traducciones inglesas de los segmentos narrados en francés y otros manuscritos. Todo presentado en forma de barras horizontales paralelas que delimitan una pantalla principal sobre la cual se desarrollarán las actividades seleccionadas. Los vínculos se hacen siempre por medio de la activación de objetos-signos distribuidos en el plano, seguidos a veces por indicios sonoros como el timbre de un teléfono que nos permite escuchar a Maude Laures confiar a su amiga Hélène sus sinsabores de docente y su deseo de traducción.

La autorreferencialidad del procedimiento de apropiación está fuertemente afirmada en la página titulada The Maker invocada por un ícono de un documento en la guantera. Esta pantalla presenta una cantidad de botones con la efigie de los pictogramas de ruta dispuestos en juegos de pistas sobre la cara de la autora en posición frontal (ilustración 5). Las señales introducen a diversas dimensiones de lo pro-multimediático: notas tomadas por Adriene Jenik durante el trabajo relatando sus propios sentimientos; segmentos videográficos que relatan la filmación de ciertas escenas; un álbum de fotografías de la muchacha joven (Lora Moran ${ }^{15}$ ) que personifica a Mélanie; un resumen de la correspondencia con Nicole Brossard donde se reproduce de alguna forma el diálogo imaginado por Maude Laures con Laures Angstelle en la escena IV de la novela (pp. 140-143); guiños humorísticos; una serie de veinte preguntas que han preocupado a la artista a lo largo de la ejecución de su trabajo: "Why is this book so important to me? (¿Por qué este libro es tan 
importante para mí?) How should it end? (¿Cómo debería terminar?) Am I bound to Brossard's ding? (¿Estoy atada al sonido de la campana de Brossard?) What is happening to me? (¿Qué me está pasando?)”; y finalmente el cuadro esquemático de la estructura general de navegación de la obra que constituye el plan de encaje de las diferentes páginas y de los vínculos hipertextuales que les dan acceso (ilustración 6). Este diagrama representa en suma la reconstrucción del hilo de Ariadna reticular expuesto en su desnudez funcional.

Como la traducción, la adaptación opera en la confluencia de registros de lo mismo y de lo otro en una serie de actos identificatorios y distanciadores destinados a conducir la significación de una forma de expresión a otra. Las dos están sometidas al tamizado de los filtros culturales que moldean la recepción del sujeto performador de la transposición. Esto es particularmente visible en Mauve Desert donde la búsqueda de equivalencias está fuertemente impregnada de resonancias biográficas suscitadas por la factura mimética de la novela de Nicole Brossard. El deseo de traducción provocado en Maude Laures por el descubrimiento del manuscrito de Laure Angstelle prolonga su hechizo en su transposición multimediática. El reto consistente en reverberar el espíritu de la obra primera ha sido logrado por una serie de estrategias autoreferenciales de apropiación que exceden al hipotexto y constituye de hecho una crítica de identificación del mismo. La adaptación calca así el proceso de la traductora intradiegética y haciendo esto participa, según la expresión de Christine Klein-Lataud, de una "traducción de ruptura" conforme a "la estética de ruptura" del hipotexto ${ }^{16}$.

Aún cuando forme parte de la misma familia audiovisual, el multimedia se distingue del cine al instituir el enunciador empírico como interactor en el dispositivo. En este sentido dirige acciones físicas de consulta y de hojeado que lo acerca a la frecuentación del libro. Según esté en fase de desciframiento de textos o de visión de secuencias videográficas, el interactor asume simultáneamente los roles de lector y de espectador, y subsume cada uno de estos status cuando se enuncia empíricamente en el proceso narrativo. En un momento dado, esta actividad conduce a abandonar el CD-ROM por la lectura del libro, en una serie de idas y vueltas que multiplican los placeres del texto construyendo un tercer término en una relación circular. Los dos medios se nutren uno al otro, se enriquecen y contribuyen a una mejor comprensión de la obra que circula en alguna parte entre y por encima de sus versiones. El próximo paso consistiría en acoplar el CD-ROM a una red hipermedia para realizar lo que Pamini llama "un instrumento para leer" distinto de los "productos para leer" (o Expanded Books) que dominan la edición electrónica ${ }^{17}$. El interactor se beneficiaría entonces de recursos documentales, biográficos, bibliográficos, críticos y de otro tipo solicitados como ayudantes del texto, como es el caso, en estado embrionario, de los segmentos de la entrevista realizada por Nicole Brossard donde expone sus procedimientos de autora. La lectura se extendería así a las dimensiones de una biblioteca virtual según diversas modalidades propias de la cultura de la interactividad, favoreciendo a un mismo tiempo a la investigación, la creación y la re-creación. 


\section{Notas}

${ }^{1}$ Colaboración enviada por su autor. Artículo inicialmente publicado en Cinéma et littérature au Québec: rencontres médiatiques, sous la direction de Larouche, M., Montréal, XYZ, 2002, pp. 41-52.

${ }^{2}$ Jenik, A. (1996). Mauve Desert, a Cd-Rom translation (Based upon the novel Le désert mauve by Nicole Brossard). Los Angeles: Shifting Horizons Productions).

Ver [http://home.earthlink.net/ - depop/indexmd.html]

${ }^{3}$ Ver el artículo que hemos consagrado a este tema: "Hybridation et métissage sémiotique. L'adaptation multimédiatique" en Applied Semiotics / Sémiotique appliquée (AS/SA), No 9, p. 511-520.

[http:www.chass.utoronto.ca/french/as-sa/ ]

${ }^{4}$ Klein-Lataud, C. "Traduction et plaisir du texte". Protée, vol. 25, No 3, hiver 1997-1998, pp. 31-38, p. 34.

${ }^{5}$ Dos concepciones pertinentes del hipertexto convergen aquí: primero la que lo encara desde un punto de vista informático en tanto que : "[...] nonsequential writing -text that branches and allows choices to the reader, best read at an interactive screen. As popularly conceived, this is a series of text chunks connected by links which offer the reader different pathways". Nelson, T.H., Literary Machines (SwarThMORE, PA.: self published, 1981), 0/2, dans Landow, G., Hypertext. The convergence of Contemporary Critical Theory and Technology. The Johns Hopkins University Press, Baltimore and London, 1992, p. 4; Segundo, la que lo define desde un punto de vista poético en tanto que "(...) texto derivado de un texto anterior por transformación simple (diremos de aquí en más sólo transformación) o por transformación indirecta: diremos imitación." GenetTe, G., Palimpsestos. La literatura en segundo grado, Seuil, París, 1982, p. 14.

${ }^{6}$ Ver por ejemplo: Pamini, A. "Alice au pays des hypertextes. Modèle pour un hypertexte de recherche" en Banque de données et hyper-textes pour l'étude du roman, sous la direction de Nathalie Ferrand. Presses Universitaires de France, 1997. pp. 155-181, p. 167.

${ }^{7}$ El procedimiento no deja de recordar las concepciones de Proust o de Baudelaire en cuanto a la crítica literaria que debe en un primer tiempo identificarse, hasta confundirse literalmente con el objeto contemplado para apreciarlo mejor en todas sus dimensiones y así estar en mejores condiciones para transmitir su quintaesencia por las vías de una crítica identificatoria. Es de alguna manera lo que reproduce aquí el trabajo creador de Adriene Jenik quien confiesa, en los interrogantes que incorpora a su traducción (cf. la página titulada The Maker), que se pregunta sobre la fascinación que ejerce sobre ella el libro de Brossard, parecida a la fascinación intradiegética ejercida por la novela de Laures Angstelle sobre Maude Laures. Ver Poulet, G., La consciente critique, Librairie José Corti, 1971.

${ }^{8}$ Hotтe, L. "La partie et le tout : fragmentation et union dans Le dé-sert Mauve de Nicole Brossard”. Littératures, No 11, 1993, pp. 53-66.

${ }^{9}$ Tomamos estos conceptos de George Zénatti para quien la interactividad puede inscribirse según cuatro tipos: interfaz lineal (cada pantalla está unida de manera única a lo que le precede), en arborescencia (una pantalla principal da acceso a pantallas secundarias, luego a ramificaciones), no-lineal (a partir de cada pantalla el utilizador puede alcanzar todas las otras); compuesta (algunas continuaciones de pantallas son lineales y otras no-lineales) en CD-Rom et Vidéo-CD, Hermès, París, 1995, pp. 65-66. 
${ }^{10}$ Cohen, D. "Interfactives ou l'écran agi. I-Les métaphores à l'écran" en Écrit. Images. Oral et Nouvelles technologies. Actes du séminaire 19941995, sous la responsabilité de Marie-Claude Vettraino-Soulard, Université Paris7-Denis Diderot, pp. 77-105, p. 85.

${ }^{11}$ Como nos lo ha confirmado la autora.

${ }^{12}$ Estos dos juegos que rápidamente se han elevado al rango de clásicos del género son la obra de Rick Barba y Rusel DeMaria. Han sido publicados en Boderbund Software, Cleveland, Royaume-Uni, respectivamente en 1995 y 1997 . [http://www.riven.com/]

${ }^{13}$ Igualmente confirmado por la autora.

${ }^{14}$ Cohen, D., "Interfaces interactives: les partitions de l'écran" en Écrit, image, oral et nouvelles technologies. Actas del seminario 1995-1996, bajo la responsabilidad de Marie-Claude Vettraino-Soulard, Université Paris7Denis Diderot, pp. 169-189.

${ }^{15}$ Es de notar la afinidad de asonancia con Laura Angstelle y Maude Laures.

${ }^{16}$ Klein-Lataud, C., ob.cit., p. 33.

${ }^{17}$ Pamini, A., ob.cit., p. 165 (en cursivas en el texto). 